\title{
CONCURRENT VALIDITY AND RELIABILITY OF 3-DAY PHYSICAL ACTIVITY RECALL ON DAILY ENERGY EXPENDITURE IN CHILDREN AND ADOLESCENTS
}

original paper

( ) University School of Physical Education in Wroclaw

DOI: https://doi.org/10.5114/hm.2021.100018

\section{VINICIUS OLIVEIRA DAMASCENO ${ }^{1}$, JORGE ROBERTO PERROUT LIMA ${ }^{2}$, REGINALDO GONÇALVES ${ }^{3}$, JEFERSON MACEDO VIANNA ${ }^{2}$, FRANCISCO ZACARON WERNECK ${ }^{4}$, PAULO ROBERTO AMORIM ${ }^{5}$, DALTON LIMA-JÚNIOR ${ }^{1}$, JOEL ALVES LAMOUNIER}

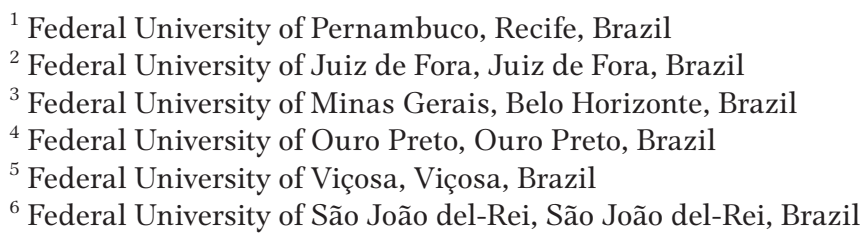

\section{ABSTRACT}

Purpose. The aim of this study was to validate the 3-Day Physical Activity Recall (3DPAR) for measuring daily energy expenditure in children and adolescents.

Methods. Children and adolescents, a total of 148 participants, were recruited in 10 schools. The data collection was carried out in a period of 11 months. The measurements of weight, skinfold, and circumferences were performed. After the anthropometric assessment, an accelerometer was put on and the participant remained with the electrodes during 5 days. On the fifth day, the accelerometer was taken off and 3DPAR was applied. After 1 week of the study (eighth day), 3DPAR was applied again for testing reliability.

Results. In the analysis of reliability and internal consistency, Cronbach's alpha was 0.73 for the first assessment of 3DPAR and 0.83 for the second one. The consistency of the values estimated by 3DPAR yielded Cronbach's alpha of 0.89 in the first assessment and 0.83 in the second one. The correlations and the coefficient of determination between 3DPAR and the accelerometer were considered moderate and significant $(r=0.645, p<0.001)$.

Conclusions. 3DPAR presented satisfactory reliability and moderate correlations with the criterion measurement in children and adolescents aged 10-12 years.

Key words: obesity, physical activity, questionnaire, self-report

\section{Introduction}

In the recent decades, the prevalence of obesity in children and adolescents has been increasing worldwide [1]. In 2025, the number of overweight and obese children might reach over 260 million and 91.2 million, respectively [2]. Consequently, the incidence of chronic diseases related to obesity, such as hyperlipidaemia, hypertension, or diabetes, is increasing as well, even though these are not usual in children [2, 3].
Reducing or stopping the development of chronic diseases in children and adolescents is essential to a healthy life in adulthood. Regarding obesity control, daily energy expenditure (DEE) might play an essential role as the kilocalorie expenditure might contribute to limiting obesity and, consequently, the chronic diseases related to the dysfunction $[4,5]$. Furthermore, to validate instruments that measure DEE to evaluate the prevalence, influence, and effect of physical activity in children and adolescents is crucial [5-7]. Although

Correspondence address: Vinicius Oliveira Damasceno, Department of Physical Education, Federal University of Pernambuco, Cidade Universitária, Recife, State of Pernambuco ZIP-code: 50730-120, Brazil, e-mail: vinicius.damasceno@gmail.com

Received: April 21, 2019

Accepted for publication: March 24, 2020

Citation: Damasceno VO, Lima JRP, Gonçalves R, Vianna JM, Werneck FZ, Amorim PR, Lima-Júnior D, Lamounier JA. Concurrent validity and reliability of 3-Day Physical Activity Recall on daily energy expenditure in children and adolescents. Hum Mov. 2021;22(2):93-101; doi: https://doi.org/10.5114/hm.2021.100018. 
the methods of determining DEE such as doubly labelled water are accurate, their application is expensive and laborious, especially when concerning several individuals. For this reason, an accelerometer has been used as an alternative method to measure physical activity [8-11] and energy expenditure [12]. Actiheart ${ }^{\circledR}$ is a uniaxial accelerometer that combines movement and heart rate evaluation. In laboratory and field studies, Actiheart ${ }^{\circledast}$ showed strong and good correlations for estimating the level of physical activity and DEE with the methods of direct observation (e.g., heart rate, indirect or direct calorimetry, and doubly labelled water) [12-15]. Besides, Actiheart ${ }^{\circledast}$ presents excellent reproducibility. However, in studies with large samples, the use of accelerometry is still hard to perform. In Brazil, only 2 studies with accelerometry were published by 2014 . Thus, questionnaires are highly recommended in huge samples owing to their feasibility and low cost.

Consequently, several studies have adopted questionnaires [16-23], and the 3-Day Physical Activity Recall (3DPAR) or similar versions (i.e., Previous-Day Physical Activity Recall or 7-Day Physical Activity Recall) is largely used for physical activity assessment [16, 17, 24-30]. In Brazil, Goulart et al. [31] tested the psychometric qualities (i.e., reliability and construct validity) of 3DPAR in 216 adolescents (13-19 years), but the article remains unpublished in the full-text version. 3DPAR was not validated for measuring DEE in children and adolescents and studies have applied adult physical activity compendiums to estimate DEE [32]. Moreover, 3DPAR evaluates not only physical activity, but also DEE [5]. Considering the physiological differences between age groups and the increased prevalence of obesity in children and adolescents, the validity of 3DPAR for measuring DEE is highly relevant. Thus, this study aimed to establish the concurrent validity and reliability of 3DPAR to measure DEE in children and adolescents.

\section{Material and methods}

\section{Participants}

A cross-sectional study was performed. The study population consisted of 621 schoolchildren aged 10-12 years enrolled from fifth to seventh grades of public schools in São João Nepomuceno, state of Minas Gerais, Brazil.

The inclusion criteria involved children and adolescents aged 10-12 years, healthy and able to practise physical activities. Also, the subjects should not have presented any chronic illnesses or used any medicine that could cause heart rate alterations. We did not include children or adolescents from schools with less than 100 students, as well as from public schools that reached a score below $60 \%$ in the national score test (Provinha Brasil). After inclusion, if any error occurred during the accelerometer assessment that impaired data analysis or if the accelerometer failed to collect 10 hours of data each day, we excluded the participant from the study.

In accordance with the inclusion and exclusion criteria, 2 elementary schools with more than 100 children and adolescents each were selected, representing 421 students enrolled between fifth and seventh grade. To ensure a study power of $95 \%$ and an alpha error of 3\%, the minimum sample should be 111 children and adolescents aged 10-12 years. However, after estimating a loss of $90 \%$, the final sample consisted of 208 individuals. For the sample calculation, we used the $G^{*}$ Power version 3.1 software. With the consideration of the data obtained in the 2 schools, students were numbered in sequence. Then, by using a table of random numbers by Excel 2003 (Microsoft Corporation, Redmond, USA), the corresponding number of children was selected in the list, until the number to compose the sample was reached.

Overall, 40 students dropped out of the study because of device problems and 5 for inconsistent data on 3DPAR. The problems related to the device were the following: 4 participants had allergy wearing it on the first day, 12 presented allergy on the second day, and 3 on the third day; moreover, 21 subjects reported allergy during the study but remained with the device all 3 days long. One child damaged the device on the first day. Also, 20 participants were excluded because of time recording (i.e., < 10 hours per day). After accelerometer data normalization, 148 participants were analysed.

\section{Data collection}

The data collection was carried out within 11 months, during February and June of 2012 in the first school, and during July and December of the same year in the second school.

\section{Anthropometric measurements}

Each participant was anthropometrically assessed in private rooms. The measurements of weight, skinfold, as well as the waist, hip, and abdomen circumferences were performed. During the assessment, socio-demographic questionnaires were filled in by the parents; 
also, an informative paper about the appropriate use of the accelerometer was given to them.

Bodyweight was evaluated with digital scales (Seca 877 , Australia) with a maximum capacity of $150 \mathrm{~kg}$ and accuracy of $0.1 \mathrm{~kg}$, whereas height was determined by using a stadiometer (Alturaexata, Brazil) with a scale of 1-213 $\mathrm{cm}$ and accuracy of $0.1 \mathrm{~cm}$.

Circumferences of the waist, abdomen, and hip were measured with a tape (Sanny ${ }^{\circledR}$, Brazil). Triceps, abdomen, subscapular, and medial calf skinfolds were determined with an adipometer (Lange Skinfold Caliper ${ }^{\circledR}$ ) ranging from 0 to $60 \mathrm{~mm}$ with an accuracy of $1 \mathrm{~mm}$. The examinations were carried out by a professional with more than 10 years of experience and in accordance with the International Society for the Advancement of Kinanthropometry [33] norms. The body fat equation used in this study was developed by Slaughter et al. [34].

\section{Accelerometer}

The accelerometer (Actiheart ${ }^{\circledR}$, Cambridge Neurotechnology Ltd, Papworth, UK) was put on the thoracic region of the participants. The area was cleaned up with alcohol and the electrode (Red Dot 3M) was placed. The subjects remained with the electrodes for 5 days (Wednesday, Thursday, Friday, Saturday, and Sunday), even though data were collected only on Thursday, Friday, and Saturday. The accelerometer has the weight of $8 \mathrm{~g}$, length of $7 \mathrm{~mm}$, and diameter of $33 \mathrm{~mm}$. It contains a movement sensor able to measure horizontal and vertical acceleration, heart rate, DEE, and electrocardiographic parameters during a predetermined time [35].

On the fifth day of the study (Sunday), the researchers visited the participant's homes to take the accelerometers off. Two questions were asked: 'Did you feel uncomfortable wearing it?' and 'Did you have any kind of allergy wearing it?' The accelerometer data were downloaded in the Mini Mitter, Actiheart v. 2.2 software. The Actiheart ${ }^{\circledast}$ software provides DEE without adding any more information such as basal metabolic rate. Thus, to obtain net DEE $\left(\mathrm{kcal} \cdot \mathrm{day}^{-1}\right)$, the Schofield equation value [36] was summed up with the accelerometer values.

\section{SDPAR}

3DPAR is a questionnaire that allows individuals to remember the physical activities of the previous 3 days, within intervals of 15 minutes, from 06 to 24 hours or during the subject's awake time. The questionnaire is composed of 62 options of activities that the participant might perform during a regular day. To increase the accuracy of the questionnaire, the activities were grouped up in 6 categories: eating, after school/spare time/hobbies, transportation, sleeping/ bathing, school, and physical activities/sports. The individuals observed the activities and filled in the questionnaire in accordance with the performed activities. Then, an X was marked for the corresponding effort level (light, moderate, high, or very high). Light intensity was described as having mild respiration, without or with small movements. Moderate intensity was characterized by normal respiration and some movements [37]. High intensity was established when respiration was increased, with intense movements. Very high intensity occurred with accelerated respiration and a high increase in movement intensities.

3DPAR, recently adopted for Brazilian Portuguese [38], was applied on Sunday, after removing the accelerometer. In order not to leave any questions unanswered, the participants started reporting the physical activities performed during 3 consecutive days: Thursday, Friday, and Saturday. The mean time spent on filling in the questionnaire was $28.1 \pm 16.7$ minutes (recorded by the evaluator). Parents, guardians, or anyone else did not intervene in the answers. 3DPAR makes 2 measurements possible: DEE $\left(\mathrm{kcal} \cdot \mathrm{day}^{-1}\right.$ or $\mathrm{kcal} \cdot \mathrm{kg}^{-1} \cdot$ day $^{-1}$ ) and time devoted to efforts of different intensities: sedentary, light, moderate, high, and very high. On the eighth day of the study, 3DPAR was administered again for reliability.

3DPAR data were saved with Hypertext Preprocessor (PHP) Web software developed specifically to calculate DEE. To estimate DEE by using 3DPAR, a compendium by Ridley et al. [20] designed for children and adolescents was applied.

\section{Statistical analysis}

All data were presented as means and standard deviations. The Kolmogorov-Smirnov test was used to verify the normality of data. Student's paired $t$-test was applied to establish the differences between DEE values determined by different methods (3DPAR and the accelerometer). Cronbach's alpha served to test the reliability and consistency of 3DPAR. To assess the concurrent validity between $3 \mathrm{DPAR}$ and the accelerometer, values for DEE were tested by Pearson correlation. Next, the Bland-Altman plot was used to verify the equivalence of DEE between the methods. To establish the intra-individual 3DPAR reliability, the intraclass correlation coefficient (ICC) was applied. All the analyses were performed with the SPSS v. 21.0 software. The alpha value adopted in this study equalled 0.05. 


\section{Ethical approval}

The research related to human use has complied with all the relevant national regulations and institutional policies, has followed the tenets of the Declaration of Helsinki, and has been approved by the Paediatric Department of Medicine, Federal University of Minas Gerais (No. 26/10) and the Human Research Ethics Committee, Federal University of Minas Gerais (No. 0396.0.203.000.10).

\section{Informed consent}

Informed consent has been obtained from the parents or legal guardians of all individuals included in this study. All the examined students assented to participate.

\section{Results}

Table 1 presents the anthropometric characteristics of the participants.

In the analysis of reliability and internal consistency, Cronbach's alpha was 0.73 for the first 3DPAR assessment and 0.83 for the second one. The consistency of the values in $\mathrm{kcal}^{-}$day $^{-1}$ estimated by 3DPAR yielded Cronbach's alpha of 0.89 for the first assessment and 0.83 for the second one.

Reliability was measured by ICC. The analyses carried out per day presented an ICC of 0.74 for Thursday (Thursday 1 vs. Thursday 2, ICC 95\% CI: 0.64-0.81, $p<0.001$ ), 0.80 for Friday (Friday 1 vs. Friday 2, ICC
95\% CI: $0.72-0.86, p<0.001$ ), and 0.71 for Saturday (Saturday 1 vs. Saturday 2, ICC 95\% CI: 0.61-0.80).

Figure 1 shows a comparison of DEE values of 3DPAR for Thursday, Friday, and Saturday in the test and retest assessments. There was no difference between the test and retest (Thursday 1 vs. Thursday 2, $t_{(147)}=1.033, p=0.30$; Friday 1 vs. Friday $2, t_{(147)}=0.59$, $p=0.56$; Saturday 1 vs. Saturday $2, t_{(147)}=1.62, p=0.11$ ).

Table 2 presents the descriptive information on DEE as measured with the accelerometer and with 3DPAR.

As for the correlations and coefficients of determination for DEE ( $\mathrm{kcal} \cdot \mathrm{day}^{-1}$ ) between 3DPAR and accelerometer measurements, the values were considered

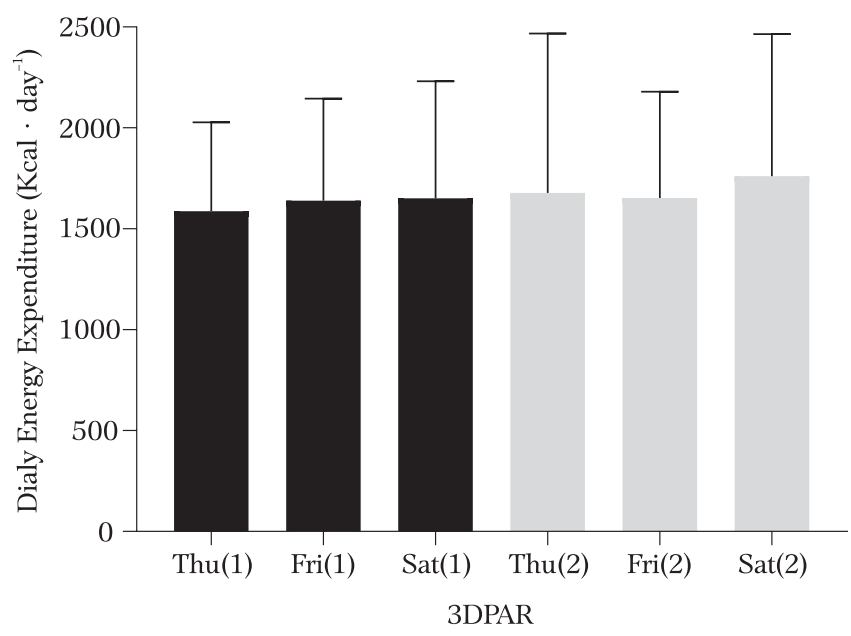

Figure 1. Comparison of 3-Day Physical Activity Recall (3DPAR) test and retest for daily energy expenditure

Table 1. Anthropometric characteristics of the sample $(n=148)$

\begin{tabular}{lcccccc}
\hline & \multicolumn{2}{c}{ All (148) } & \multicolumn{2}{c}{ Boys (76) } & Girls (72) \\
\cline { 2 - 7 } Characteristics & Mean (SD) & $95 \%$ CI & Mean (SD) & $95 \%$ CI & Mean (SD) & $95 \%$ CI \\
\cline { 2 - 7 } & & & & & & \\
\hline Age (years) & $10.99(0.81)$ & $10.85-11.11$ & $11.04(0.78)$ & $10.85-11.22$ & $10.9(0.82)$ & $10.75-11.11$ \\
Body mass (kg) & $43.93(10.51)$ & $42.39-45.96$ & $42.23(10.54)$ & $40.73-45.72$ & $44.72(10.38)$ & $42.48-46.96$ \\
Height (m) & $1.50(0.08)$ & $1.49-1.51$ & $1.50(0.08)$ & $1.48-1.52$ & $1.50(0.07)$ & $1.48-1.52$ \\
Body fat (\%) & $25.04(10.0)$ & $23.45-26.62$ & $23.37(10.80)$ & $20.78-25.97$ & $26.42(9.10)$ & $24.45-28.38$ \\
Body fat (kg) & $11.72(7.07)$ & $10.60-12.84$ & $10.82(7.35)$ & $9.07-12.58$ & $12.46(6.88)$ & $10.99-13.92$ \\
Lean mass (kg) & $32.22(5.69)$ & $31.36-33.20$ & $30.87(5.99)$ & $30.87-33.72$ & $32.26(5.64)$ & $31.04-33.48$ \\
\hline
\end{tabular}

Table 2. Descriptive information on daily energy expenditure measures on the accelerometer and 3DPAR

\begin{tabular}{|c|c|c|c|c|c|c|}
\hline \multirow{2}{*}{ Groups } & \multicolumn{3}{|c|}{ Accelerometer DEE $\left(\mathrm{kcal} \cdot \mathrm{day}^{-1}\right)$} & \multicolumn{3}{|c|}{ 3DPAR DEE $\left(\mathrm{kcal} \cdot \mathrm{day}^{-1}\right)$} \\
\hline & Friday & Thursday & Saturday & Friday & Thursday & Saturday \\
\hline All & $1895.8(512.5)$ & $1954.3(538.9)$ & $1875.0(557$ & $1559.8(423.39)$ & 1630 (452.7) & $1671.7(6$ \\
\hline Boys & 2145.7 (555.5) & $2230.0(536.7)$ & $2157.6(578.4)$ & $1575(446.2)$ & $1655.2(555.9)$ & $1762.5(749.5)$ \\
\hline Girls & $1693.9(369.7)$ & $1721.1(419.4)$ & 1632.7 (408.0) & $1546.6(405.5)$ & $1608.9(420.4)$ & $1594.5(447.4)$ \\
\hline
\end{tabular}

Data presented as mean $(S D)$.

3DPAR - 3-Day Physical Activity Recall, DEE - daily energy expenditure 

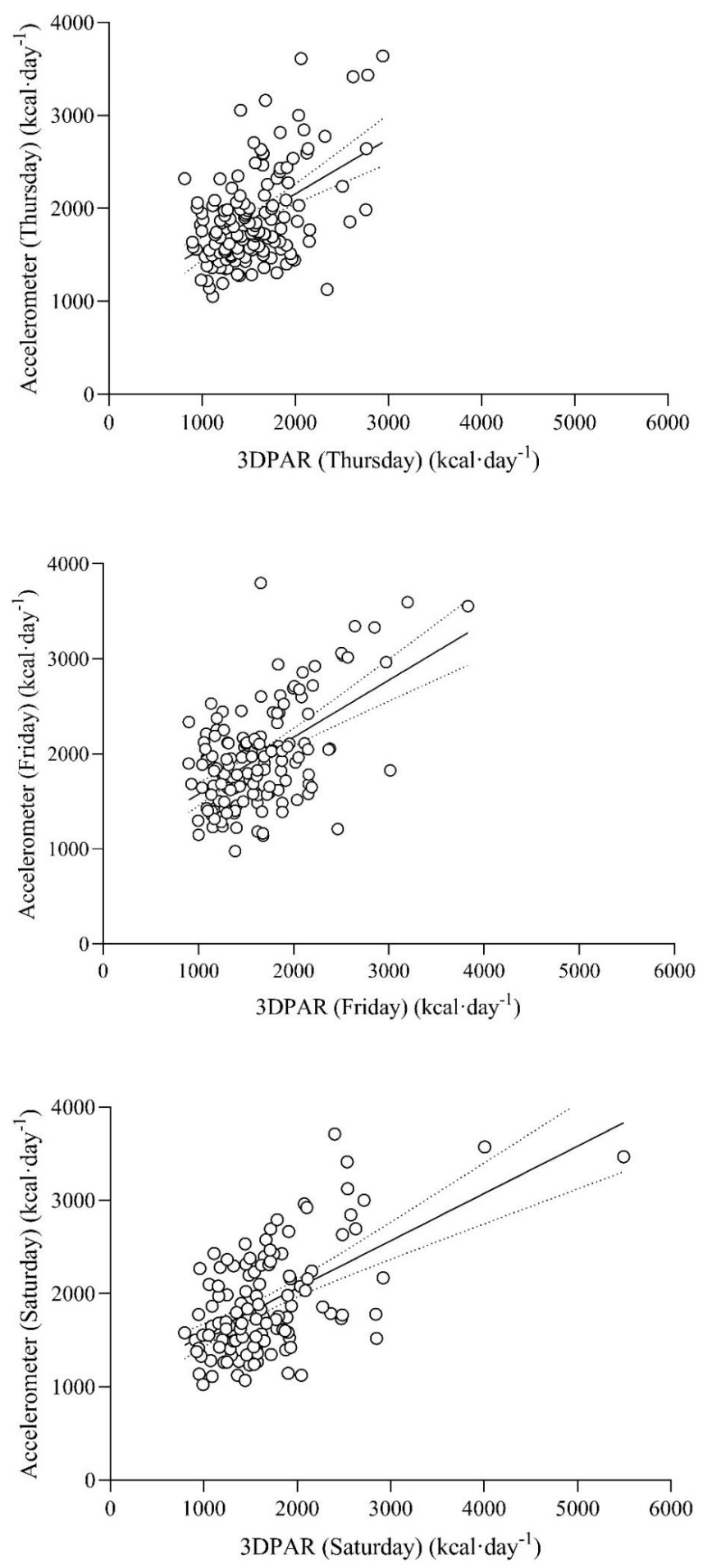

Figure 2. Correlations between daily energy expenditure measured by the 3-Day Physical Activity Recall (3DPAR) and the accelerometer per day

moderate and significant: accelerometer DEE for Thursday vs. 3DPAR DEE for Thursday, $r=0.570, p<0.001$; accelerometer DEE for Friday vs. 3DPAR DEE for Friday, $r=0.610, p<0.001$; accelerometer DEE for Saturday vs. 3DPAR DEE for Saturday, $r=0.630, p<0.001$ (Figure 2).
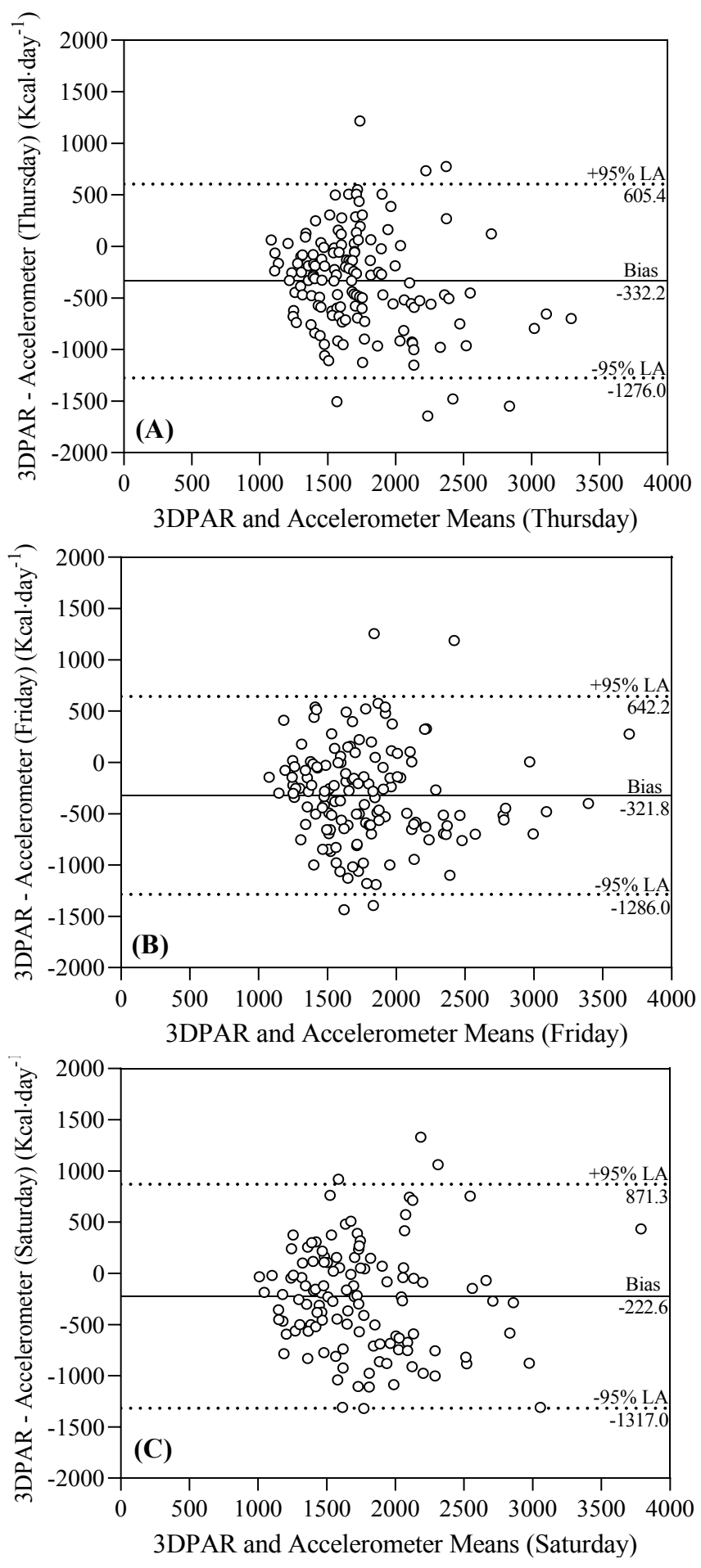

LA - limit of agreement

Figure 3. Bland-Altman plot for the 3-Day Physical Activity Recall (3DPAR) and accelerometer indications per day

Table 3 shows the correlations between DEE as indicated by 3DPAR and the accelerometer per day and sex.

Error mean values of DEE between the methods for particular days are depicted in Figure 3A (333 \pm 479.9 $\left.\mathrm{kcal} \cdot \mathrm{day}^{-1}, 20 \%\right)$, Figure 3B (321 $\pm 491.9 \mathrm{kcal} \cdot \mathrm{day}^{-1}$, $18 \%)$, and Figure 3C $\left(222 \pm 558.1 \mathrm{kcal} \cdot \mathrm{day}^{-1}, 12 \%\right)$. 
V.O. Damasceno et al., 3DPAR validity in children and adolescents

Table 3. Correlations between daily energy expenditure measured by the accelerometer and 3DPAR and per day and sex

\begin{tabular}{lcccccc}
\hline & \multicolumn{5}{c}{ Accelerometer vs. 3DPAR correlations } \\
\cline { 2 - 7 } Groups & \multicolumn{2}{c}{ Friday } & \multicolumn{2}{c}{ Thursday } & Saturday \\
\cline { 2 - 7 } & $r$ & $95 \%$ CI & $r$ & $95 \%$ CI & $r$ & $95 \%$ CI \\
\hline All & $0.56^{*}$ & $0.45-0.68$ & $0.55^{*}$ & $0.42-0.65$ & $0.56^{*}$ & $0.43-0.67$ \\
Boys & $0.69^{*}$ & $0.56-0.82$ & $0.73^{*}$ & $0.60-0.86$ & $0.67^{*}$ & $0.54-0.80$ \\
Girls & $0.61^{*}$ & $0.48-0.74$ & $0.60^{*}$ & $0.46-0.72$ & $0.59^{*}$ & $0.43-0.70$ \\
\hline
\end{tabular}

3DPAR - 3-Day Physical Activity Recall

${ }^{*} p<0.001$

\section{Discussion}

The results provided evidence for moderate validity of 3DPAR in assessing DEE among children and adolescents aged 10-12 years when compared with the criterion measurement. DEE values for 3DPAR and the accelerometer yielded similar results on Thursday and Saturday.

As for the criterion validity, Eklund et al. [39] used heart rate for comparisons; nevertheless, they did not find any difference between DEE estimated by 3DPAR and heart rate in 30 adolescents $(15.0 \pm 1.0$ years of age). In this study, the internal consistency presented by Cronbach's alpha values equalled 0.73 for test and 0.86 for retest. The results were similar to those of 2 different studies $[40,41]$ that revealed good internal consistency of measuring DEE.

Regarding reliability, in a study by Sallis et al. [42], performed in a sample of 112 adolescents (15-18 years old), the 7-Day Physical Activity Recall (7DPAR), a physical activity diary similar to 3DPAR, yielded ICC of 0.77 ( 1 week between tests). In another study, Lee and Trost [7] assessed the reliability of 3DPAR among 221 Singaporean adolescents (13-16 years old), achieving an ICC of 0.90 ( 8 hours between tests). Pavlidou et al. [41] tested 3DPAR reliability in 61 children of both sexes (10-11 years old); after 1 week, a retest was applied, yielding an ICC of 0.61 for the 3 consecutive days. De Farias Júnior [43] evaluated reliability in a sample of 45 adolescents aged $15-18$ years (16.00 \pm 1.28 ). The test and retest had an interval of 24 hours, showing an ICC of 0.84 (95\% CI: 0.73-0.91). Argiropoulou et al. [44] investigated 3DPAR reliability among 40 adolescents $(13.5 \pm 0.8$ years old $)$ in 1 week, yielding an ICC of $0.97(p<0.001)$. In the present study, 3DPAR demonstrated an ICC of 0.70 in 1 week between test and retest. Although we measured crude DEE (kcal) and the studies cited above determined DEE as MET $\cdot \min ^{-1}$, total MET, moderate to vigorous physical activity (min), and vigorous physical activity (min), the reliability remained satisfactory for intra-individual assessment and test-retest [5, 45-47].

With reference to the criterion validity, the mean Pearson correlation value was $0.58(p<0.001)$, considered moderate. Studies that validated 3DPAR using an accelerometer [5, 37, 40, 41, 44-49] or pedometer $[7,40]$ in children and adolescents found values between 0.40 and 0.72, all of them significant. Age groups varied between 10 and 18 years of age; however, it seems that age is not a determinant of 3DPAR validation.

In this study, crude predicted DEE of the accelerometer was correlated to DEE predicted by 3DPAR. As opposed to the studies that used pedometers (number of steps) or accelerometers (counts $\cdot \mathrm{min}^{-1}$ ) as the criterion method [46, 47, 50], DEE values predicted by our accelerometer are expressed in kilocalories, which is obtained by the association of the movement with the heart rate. Our hypothesis is that correlating measures of the same unit could bring advantages to the study on the prediction error of DEE since pedometers and accelerometers need equations to assess DEE or it is arbitrarily evaluated as an indirect measure of intensity (counts $\cdot \mathrm{min}^{-1}$ ). Even though, our measures are similar to those obtained in the other studies.

Regarding the DEE error between methods for the 3 days, the mean error is $292 \mathrm{kcal}$ (95\% CI \pm 495 $\mathrm{kcal} \cdot \mathrm{day}^{-1}$ ). Our study sub-estimated DEE $\cdot$ day $^{-1}$. Only Argiropoulou et al. [44] assessed crude DEE, although no statistical analysis was applied to it. In a study conducted by Machado-Rodrigues et al. [48] among Portuguese children and adolescents that used accelerometers, an error of $0.25 \mathrm{kcal} \cdot \mathrm{min}^{-1}$ (approximately $360 \mathrm{kcal} \cdot \mathrm{day}^{-1}$ ) was found. Also, MartínezGómez et al. [47] reported an error of 32 minutes of moderate to vigorous physical activity per day. In crude values, for a child that weighs $43 \mathrm{~kg}$, the error would be 151-333 kcal. All the other studies did not present a Bland-Altman plot [40, 41, 49]; thus, the prediction error was not assessed. Although the mean error value 
(292 kcal) could be considered small, it is important to highlight two problems. First, it is related to the limits of agreement. The values could be between $-1200 \mathrm{kcal}$ and $600 \mathrm{kcal}$, a wide range of estimates for the bias. Second, apparently a bias of approximately $292 \mathrm{kcal}$ cannot be considered low for children who have a DEE of $1500 \mathrm{kcal}$.

The present study has some limitations that should be addressed in future research. The inclusion of children and adolescents within the age range of 10-12 years might limit the generalization of data. Also, some factors could have led to an augmentation of the correlation between methods. One of them is using a specific compendium for children and adolescents, and the other is dividing an hour into 4 blocks of 15 minutes since children and adolescents have a higher variability of activities in a short period. All cited studies applied a compendium for adults and the hours were divided into 2 blocks of 30 minutes. Even though we used different compendiums and divided an hour into 4 blocks, it did not seem to influence the results since they did not differ from those obtained in other studies. As the prediction error of both methods is similar to the ones reported in the literature, the error could be ascribed to a misunderstanding of the questionnaire, mainly with reference to intensity. Some participants of our study $(n=5)$ classified an activity as intense even performing it for 4 hours. It could explain the error between the methods.

\section{Conclusions}

3DPAR presented satisfactory reliability and moderate correlations with the criterion measurement in children and adolescents aged 10-12 years but with a wide range of the limits of agreement. Thereby, despite 3DPAR being a low-cost method, feasible in large samples, it should be used with caution for DEE in children and adolescents.

\section{Acknowledgments}

The authors thankfully acknowledge all children and adolescents who made the study possible, as well as their parents, teachers, and schools for the collaboration in the project.

\section{Disclosure statement}

This study was financed by the Coordenação de Aperfeiçoamento de Pessoal de Nível Superior - Brasil (CAPES), the National Council for Scientific and Technological Development (CNPq) and FAPEMIG.

\section{Conflict of interest}

The authors state no conflict of interest.

\section{References}

1. Fryar CD, Carroll MD, Ogden CL. Prevalence of overweight, obesity, and severe obesity among children and adolescents aged 2-19 years: United States, 1963-1965 through 2015-2016. NCHS Health E-Stats; 2018.

2. Lobstein T, Jackson-Leach R. Planning for the worst: estimates of obesity and comorbidities in school-age children in 2025. Pediatr Obes. 2016;11(5):321-325; doi: 10.1111/ijpo.12185.

3. Skinner AC, Perrin EM, Moss LA, Skelton JA. Cardiometabolic risks and severity of obesity in children and young adults. N Engl J Med. 2015;373(14):1307-1317; doi: 10.1056/NEJMoa1502821.

4. Rivera JÁ, de Cossío TG, Pedraza LS, Aburto TC, Sánchez TG, Martorell R. Childhood and adolescent overweight and obesity in Latin America: a systematic review. Lancet Diabetes Endocrinol. 2014;2(4):321-332; doi: 10.1016/S2213-8587(13)70173-6.

5. Dollman J, Stanley R, Wilson A. The concurrent validity of the 3-Day Physical Activity Recall in Australian youth. Pediatr Exerc Sci. 2015;27(2):262-267; doi: 10.1123/pes.2014-0117.

6. Dollman J, Okely AD, Hardy L, Timperio A, Salmon J, Hills AP. A hitchhiker's guide to assessing young people's physical activity: deciding what method to use. J Sci Med Sport. 2009;12(5):518-525; doi: 10.1016/j. jsams.2008.09.007.

7. Lee KS, Trost SG. Validity and reliability of the 3-day physical activity recall in Singaporean adolescents. Res Q Exerc Sport. 2005;76(1):101-106; doi: 10.1080/ 02701367.2005.10599265.

8. Brage S, Brage N, Franks PW, Ekelund U, Wareham NJ. Reliability and validity of the combined heart rate and movement sensor Actiheart. Eur J Clin Nutr. 2005;59(4): 561-570; doi: 10.1038/sj.ejcn.1602118.

9. Troiano RP, Berrigan D, Dodd KW, Mâsse LC, Tilert T, McDowell M. Physical activity in the United States measured by accelerometer. Med Sci Sports Exerc. 2008;40(1):181-188; doi: 10.1249/mss.0b013e31815a $51 \mathrm{b3}$.

10. Butte NF, Wong WW, Lee JS, Adolph AL, Puyau MR, Zakeri IF. Prediction of energy expenditure and physical activityin preschoolers. Med Sci Sports Exerc. 2014;46(6): 1216-1226; doi: 10.1249/MSS.0000000000000209.

11. Colley RC, Carson V, Garriguet D, Janssen I, Roberts KC, Tremblay MS. Physical activity of Canadian children and youth, 2007 to 2015. Health Rep. 2017;28(10):8-16.

12. Rousset S, Fardet A, Lacomme P, Normand S, Montaurier C, Boirie Y, et al. Comparison of total energy expenditure assessed by two devices in controlled and free-living conditions. Eur J Sport Sci. 2015;15(5):391399; doi: 10.1080/17461391.2014.949309. 
13. Corder K, Brage S, Wareham NJ, Ekelund U. Comparison of PAEE from combined and separate heart rate and movement models in children. Med Sci Sports Exerc. 2005;37(10):1761-1767; doi: 10.1249/01.mss. 0000176466.78408.cc.

14. Ndahimana D, Kim E-K. Measurement methods for physical activity and energy expenditure: a review. Clin Nutr Res. 2017;6(2):68-80; doi: 10.7762/cnr.2017. 6.2.68.

15. Loprinzi PD, Cardinal BJ. Measuring children's physical activity and sedentary behaviors. J Exerc Sci Fit. 2011;9(1):15-23; doi: 10.1016/S1728-869X(11)60002-6.

16. Khan A, Burton NW. Is physical inactivity associated with depressive symptoms among adolescents with high screen time? Evidence from a developing country. Ment Health Phys Act. 2017;12:94-99; doi: 10.1016/j.mhpa. 2017.03.001.

17. Roberts AJ, Yi-Frazier JP, Aitken KE, Mitrovich CA, Pascual MF, Taplin CE. Do youth with type 1 diabetes exercise safely? A focus on patient practices and glycemic outcomes. Pediatr Diabetes. 2017;18(5):367-375; doi: $10.1111 /$ pedi.12402.

18. Lockwood J, Jeffery A, Schwartz A, Manlhiot C, Schneiderman JE, McCrindle BW, et al. Comparison of a physical activity recall questionnaire with accelerometry in children and adolescents with obesity: a pilot study. Pediatr Obes. 2017;12(5):e41-e45; doi: 10.1111/ ijpo.12172.

19. López-Gil JF, Brazo-Sayavera J, García-Hermoso A, Yuste Lucas JL. Adherence to Mediterranean diet related with physical fitness and physical activity in schoolchildren aged 6-13. Nutrients. 2020;12(2):567; doi: $10.3390 /$ nu12020567.

20. Ridley K, Ainsworth BE, Olds TS. Development of a compendium of energy expenditures for youth. Int J Behav Nutr Phys Act. 2008;5:45; doi: 10.1186/1479-5868-5-45.

21. Štefan L, Kasović M, Zvonar M. Association between the levels of physical activity and plantar pressure in 6-14-year-old children. PeerJ. 2020;8:e8551; doi: 10.7717/peerj.8551.

22. Das Virgens Chagas D, Araújo DV, Gama D, Macedo L, Camaz Deslandes A, Batista LA. Translation and crosscultural adaptation of the Physical Activity Questionnaire for older Children into a Brazilian Portuguese version. Hum Mov. 2020;21(1):32-39; doi: 10.5114/ hm.2020.88151.

23. Pelegrini A, de Araujo Pinto A, Petroski EL. Agreement between body mass index and the sum of skinfolds in adolescents with different levels of physical activity. Hum Mov. 2018;19(2):11-17; doi: 10.5114/hm.2018. 74056.

24. Barr-Anderson DJ, Bauer KW, Hannan PJ, Story M, Neumark-Sztainer D. Perception vs reality: is perceived or objective proximity to physical activity opportunities in the environment more associated with recent use among adolescent girls? Women Sport Phys Act J. 2014;22(2):107-112; doi: 10.1123/wspaj.2014-0009.
25. Nightingale TE, Rouse PC, Thompson D, Bilzon JLJ. Measurement of physical activity and energy expenditure in wheelchair users: methods, considerations and future directions. Sports Med Open. 2017;3(1):10; doi: 10.1186/s40798-017-0077-0.

26. Dominick GM, Saunders RP, Dowda M, Kenison K, Evans AE. Effects of a structural intervention and implementation on physical activity among youth in residential children's homes. Eval Program Plann. 2014 ;46:72-79; doi: 10.1016/j.evalprogplan.2014.05.011.

27. Graham DJ, Bauer KW, Friend S, Barr-Anderson DJ, Nuemark-Sztainer D. Personal, behavioral, and socioenvironmental correlates of physical activity among adolescent girls: cross-sectional and longitudinal associations. J Phys Act Health. 2014;11(1):51-61; doi: 10.1123/jpah.2011-0239.

28. Rodríguez García PL, Pérez Soto JJ, García Cantó E, Rosa Guillamón A. Cross-cultural adaptation of a questionnaire that evaluates physical activity among children aged 10 and 11. Arch Argent Pediatr. 2015;113(3): 198-204; doi: 10.5546/aap.2015.198.

29. To QG, Gallegos D, Do DV, Tran HTM, To KG, Wharton L, et al. The level and pattern of physical activity among fifth-grade students in Ho Chi Minh City, Vietnam. Public Health. 2018;160:18-25; doi: 10.1016/j. puhe.2018.03.021.

30. McBrearty D, McCrorie P, Granat M, Duncan E, Stansfield B. Objective assessment of intensity categorization of the previous day physical activity recall questionnaire in 11-13 year old children. Physiol Meas. 2014;35(11):2329-2342; doi: 10.1088/0967-3334/35/ $11 / 2329$.

31. Goulart EA, Maria P, De Bem FL, Pires MC, Gomes de Barros MV, da Silva Duatce MF, et al. Reproducibility and validity of the 3 DPAR Physical Activity Questionnaire in a sample of Brazilian adolescents. Med Sci Sports Exerc. 2001;33(5):S144; doi: 10.1097/00005 768-200105001-00816.

32. Wang P-S, Huang Y-C, Wu S-FV, Wang K-M. Effects of daily energy expenditure on academic performance of elementary students in Taiwan. Jpn J Nurs Sci. 2014; 11(1):1-9; doi: 10.1111/j.1742-7924.2012.00230.x.

33. International Society for the Advancement of Kinanthropometry. International standards for anthropometric assessment. Underdale: International Society for the Advancement of Kinanthropometry; 2001.

34. Slaughter MH, Lohman TG, Boileau RA, Horswill CA, Stillman RJ, Van Loan MD, et al. Skinfold equations for estimation of body fatness in children and youth. Hum Biol. 1988;60(5):709-723.

35. Slingerland M, Borghouts LB, Hesselink MKC. Physical activity energy expenditure in Dutch adolescents: contribution of active transport to school, physical education, and leisure time activities. J Sch Health. 2012; 82(5):225-232; doi:10.1111/j.1746-1561.2012.00691.x.

36. Schofield WN. Predicting basal metabolic rate, new standards and review of previous work. Hum Nutr Clin Nutr. 1985;39(Suppl. 1):5-41. 
37. Pate RR, Ross R, Dowda M, Trost SG, Sirard JR. Validation of a 3-Day Physical Activity Recall instrument in female youth. Pediatr Exerc Sci. 2003;15(3):257-265; doi: 10.1123/pes.15.3.257.

38. Damasceno VO, Silva AC, Amorim PR, Lima JRP, Vianna JM, Gonçalves R, et al. Cross-cultural adaptation of the questionnaire Three Day Physical Activity Recall [in Portuguese]. Rev Bras Med Esporte. 2017; 23(2):93-97; doi:10.1590/1517-869220172302141856.

39. Ekelund U, Yngve A, Sjöström M. Total daily energy expenditure and patterns of physical activity in adolescents assessed by two different methods. Scand J Med SciSports. 1999;9(5):257-264; doi:10.1111/j.1600-0838. 1999.tb00243.x.

40. Pavlidou S, Michalopoulou M, Aggelousis N, Taxildaris K. Validation of a Three-Day Physical Activity Record and the SW200 pedometer in Greek children. Biol Exerc. 2011;7(1):25-39.

41. Pavlidou S, Michalopoulou M, Aggelousis N, Taxildaris K, Bounova A. Convergent validity and reliability of a three-day Physical Activity Record in Greek children. Int Q Sport Sci. 2010;1(1):1-8.

42. Sallis JF, Buono MJ, Roby JJ, Micale FG, Nelson JA. Seven-day recall and other physical activity self-reports in children and adolescents. Med Sci Sports Exerc. 1993;25(1):99-108; doi: 10.1249/00005768-1993010 00-00014.

43. De Farias Júnior JC. Association between prevalence of physical inactivity and indicators of socio-economic status in adolescents [in Portuguese]. Rev Bras Med Esporte. 2008;14(2):109-114; doi: 10.1590/S151786922008000200005.

44. Argiropoulou EC, Michalopoulou M, Aggeloussis N, Avgerinos A. Validity and reliability of physical activity measures in Greek high school age children. J Sports Sci Med. 2004;3(3):147-159.

45. Zuazagoitia A, Montoya I, Grandes G, Arietaleanizbeascoa MS, Arce V, Martinez V, et al. Reliability and validity of the 7-day Physical Activity Recall interview in a Spanish population. Eur J Sport Sci. 2014;14(Suppl. 1): S361-S368; doi: 10.1080/17461391.2012.705332.

46. Cancela JM, Lago J, Ouviña L, Ayán C. Validity of the 24-h previous day physical activity recall (PDPAR-24) in Spanish adolescents [in Spanish]. Nutr Hosp. 2015; 31(4):1701-1707; doi: 10.3305/nh.2015.31.4.8310.

47. Martínez-Gómez D, Wärnberg J, Welk GJ, Sjöström M, Veiga OL, Marcos A. Validity of the Bouchard activity diary in Spanish adolescents. Public Health Nutr. 2010; 13(2):261-268; doi: 10.1017/S1368980009990681.

48. Machado-Rodrigues AM, Figueiredo AJ, Mota J, Cumming SP, Eisenmann JC, Malina RM, et al. Concurrent validation of estimated activity energy expenditure using a 3-day diary and accelerometry in adolescents. Scand J Med Sci Sports. 2012;22(2):259-264; doi: 10.1111/j.1600-0838.2010.01155.x.

49. Stanley R, Boshoff K, Dollman J. The concurrent validity of the 3-day Physical Activity Recall questionnaire administered to female adolescents aged 12-14 years. Aust Occup Ther J. 2007;54(4):294-302; doi: 10.1111/ j.1440-1630.2007.00659.x.

50. Olds TS, Ridley K, Dollman J, Maher CA. The validity of a computerized use of time recall, the multimedia activity recall for children and adolescents. Pediatr Exerc Sci. 2010;22(1):34-43; doi: 10.1123/pes.22.1.34. 